\title{
Erratum to: Haptic-based interactive path planning for a virtual robot arm
}

\author{
C. J. Chen · S. K. Ong - A. Y. C. Nee - Y. Q. Zhou
}

Published online: 10 July 2011

(C) Springer-Verlag 2011

Erratum to: Int J Interact Des Manuf (2010) 4:113-123

DOI 10.1007/s12008-010-0088-2

Unfortunately, Ref. [8] "Mikchevitch, A., Antoine, F.: Haptically generated paths of an AFM-based nanomanipulator using potential field. In: 4th IEEE Conference on Nanotechnology, pp. 355-357 (2004)" has been published incorrectly. The correct reference is mentioned below:

Ammi, M., Ferreira, A.: "Haptically generated paths of an AFM-based nanomanipulator using potential fields". In: 4th IEEE Conference on Nanotechnology, pp. 355-357 (2004)

The online version of the original article can be found under doi:10.1007/s12008-010-0088-2.

\section{J. Chen}

Qingdao Technological University, Qingdao, Shandong, China

e-mail: ccmilitary@yahoo.com

S. K. Ong $(\varangle)$. A. Y. C. Nee

Department of Mechanical Engineering,

Faculty of Engineering, National University of Singapore,

9 Engineering Drive 1, Singapore 117576, Singapore

e-mail: mpeongsk@nus.edu.sg

A. Y. C. Nee

e-mail: mpeneeyc@nus.edu.sg

Y. Q. Zhou

Shandong University, Jinan, Shandong, China

e-mail: yqzhou@sdu.edu.cn 